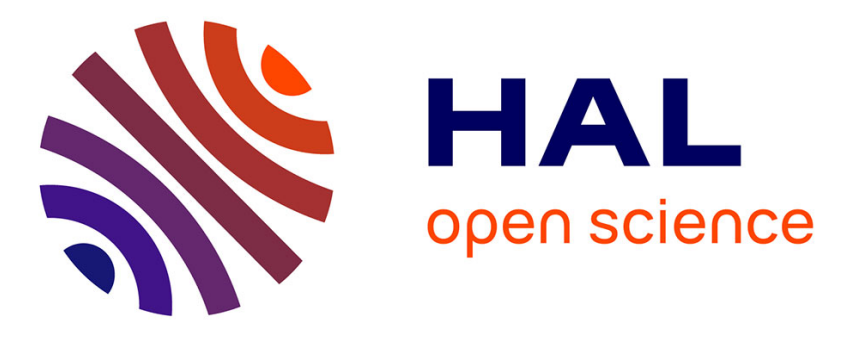

\title{
Size-Dependent Structure and Dynamics of CdS Nanoclusters
}

\author{
J. Rockenberger, L. Tröger, A. Kornowski, A. Eychmüller, J. Feldhaus, H. \\ Weller
}

\section{- To cite this version:}

J. Rockenberger, L. Tröger, A. Kornowski, A. Eychmüller, J. Feldhaus, et al.. Size-Dependent Structure and Dynamics of CdS Nanoclusters. Journal de Physique IV Proceedings, 1997, 7 (C2), pp.C21213-C2-1214. 10.1051/jp4:19972199 . jpa-00255270

\section{HAL Id: jpa-00255270 https://hal.science/jpa-00255270}

Submitted on 1 Jan 1997

HAL is a multi-disciplinary open access archive for the deposit and dissemination of scientific research documents, whether they are published or not. The documents may come from teaching and research institutions in France or abroad, or from public or private research centers.
L'archive ouverte pluridisciplinaire HAL, est destinée au dépôt et à la diffusion de documents scientifiques de niveau recherche, publiés ou non, émanant des établissements d'enseignement et de recherche français ou étrangers, des laboratoires publics ou privés. 


\title{
Size-Dependent Structure and Dynamics of CdS Nanoclusters
}

\author{
J. Rockenberger, L. Tröger*, A. Kornowski, A. Eychmüller, J. Feldhaus* and H. Weller \\ Universität Hamburg, Institut für Physikalische Chemie, Bundesstr. 45, 20146 Hamburg, Germany \\ * Hamburger Synchrotronstrahlungslabor (Hasylab), Deutsches Elektronen-Synchrotron (DESY), \\ Notkestr. 85, 22603 Hamburg, Germany
}

\begin{abstract}
CdS nanoparticles with diameters from $14-120 \AA$ and very narrow size distributions are studied by X-ray absorption fine structure spectroscopy between 5 and $296 \mathrm{~K}$. Clear trends in the Cd-S distance as a function of size and surface stabilization of the nanoparticles could be observed. Particles with thiols as ligands show an expansion of the Cd-S distance with decreasing particle size whereas polyphosphate stabilized samples are slightly contracted with respect to CdS bulk. The static disorder of the nanoparticles is enlarged with respect to the bulk. In contrast, the dynamic behavior of the nanoparticles shows a slight stiffening of the Cd-S vibration with decreasing particle size. Measurements of the third moment of the pair distribution function indicate the possibility to distinguish between cubic and hexagonal structures in CdS nanoparticles.
\end{abstract}

\section{INTRODUCTION}

The size dependent changes of structural properties of nanoparticles and their link to optical, electronic and magnetic properties are of fundamental interest in material research. However, single crystals with a three dimensional arrangement of nanocrystalline particles suitable for single crystal $\mathrm{x}$-ray diffraction (SC-XRD) can rarely be prepared. For these systems without long-range order $\mathrm{X}$-ray absorption fine structure spectroscopy (XAFS) is a well-suited method to determine structural features of these new materials. The availability of CdS nanoparticles of $14-120 \AA$ diameter with very narrow size distributions allows to resolve trends in structural and dynamical properties of these particles as a function of their size. Due to their pronounced shift of the UV-VIS absorption onset these semiconductor nanoparticles are challenging for optical applications.

\section{EXPERIMENTAL}

The preparation of the samples followed well-established and published procedures [1], [2]. In each case different amounts of $\mathrm{H}_{2} \mathrm{~S}$ were added under tigorous stirring to a solution of a $\mathrm{Cd}$ salt in water or dimethylformamide containing a stabilizer to prevent the growth of the nanoparticles to CdS bulk material. Control over the resulting nanoparticle size could be obtained by varying the type of stabilizer (thiols or polyphosphate), concentrations and heat treatment. As structural limits CdS bulk and a pure crystalline cadmium thiolate [3] which models the cluster surface have been used in the XAFS study.

We performed XAFS-measurements at the Cd K-edge between 5 and $296 \mathrm{~K}$ at the beamline X1.1 at HASYLAB/DESY (Hamburg, Germany) using a liquid He bath cryostat (OXFORD). A Si (311) double crystal monochromator was detuned to $60 \%$ of its Bragg intensity to eliminate the contributions of higher harmonics. The absorption spectra of the sample and a $\mathrm{Cd}$-metal reference foil were recorded between 26.4 and $29.0 \mathrm{keV}$ in transmission mode. Theoretical backscattering amplitudes and phases were calculated with the FEFF5 code [4]. XAFS data analysis was performed with AUTOBK and FEFFIT [5] by simultaneously fitting all spectra of one sample measured at different temperatures. The implemented Debye model allows to describe the temperature dependent part of the Debye-Waller factors of a sample by a single Debye temperature. The Cd-S shell was fitted in real space between 1.5 and $2.5 \AA$ with distances $R_{C d-s}$, Debye temperature $T_{D}$, a temperature independent Debye-Waller factor $\sigma^{2}$ as measure of the static disorder and the third moment $C_{3}$ of the pair distribution function as variables. The coordination number was set constant to $\mathrm{N}_{\mathrm{Cd}-\mathrm{s}}=4$ since varying additionally the coordination number did not improve the fits and results were within $10 \%$ identical to the expected fourfold coordination of the $\mathrm{Cd}$ atom.

\section{RESULTS AND DISCUSSION}

In Figure 1 the $k^{3}$-weighted $\chi(k)$-functions and their Fourier transforms at $5 \mathrm{~K}$ are shown for CdS bulk and $40 \AA$ CdS nanoparticles. In all samples the peak of the Cd-S coordination shell in the Fourier transform is very similar in position, height and width. In contrast, the $\mathrm{Cd}-\mathrm{Cd}$ peak of the second coordination shell vanishes very quickly with decreasing particle size and could not be detected for nanoparticles less than $30 \AA$ in size.

For all samples, the results of the fitting procedure for the Cd-S distance shift, $\Delta R_{\mathrm{Cd}-\mathrm{s}}$, and the shift in the static disorder, $\Delta \sigma_{\text {stat }}^{2}$, with respect to CdS bulk are displayed in Figure 2 . It is obvious that CdS nanoparticles with thiol ligands show an expansion of the $\mathrm{Cd}$-S distance with decreasing particle size which reaches the limit of the pure cadmium thiolate modeling 

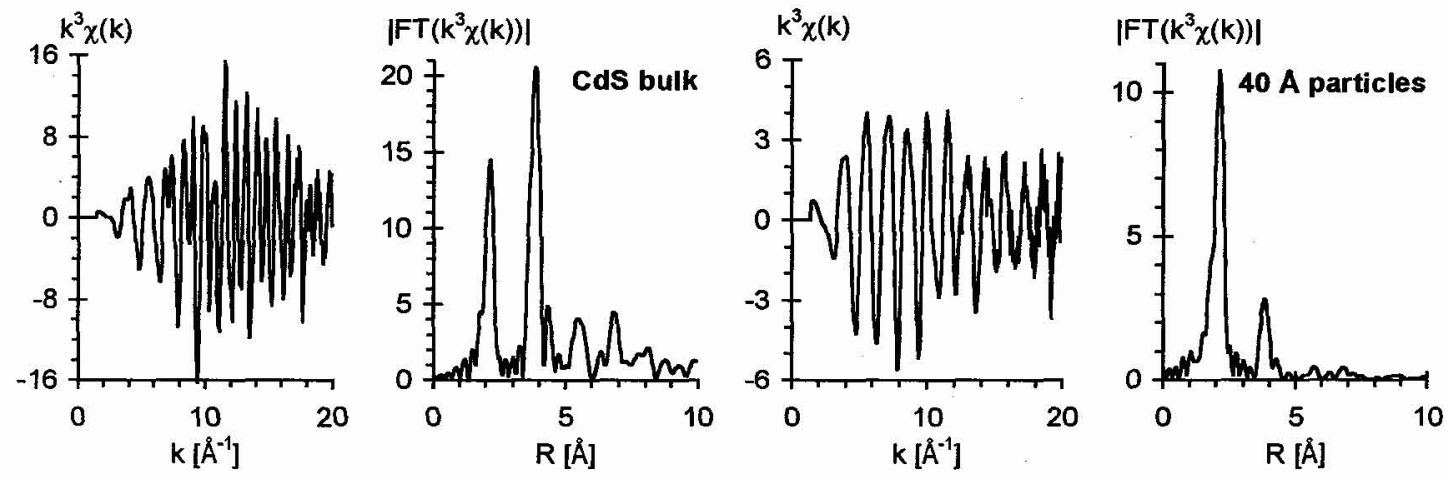

Figure 1: The $\mathrm{k}^{3}$-weighted $\chi(\mathrm{k})$-functions and their Fourier transforms for CdS bulk and CdS nanoparticles with $40 \AA$ diameter at $5 \mathrm{~K}$.

the cluster surface. Since the Cd-S distance is different in cubic and the thermodynamically favored hexagonal CdS bulk two series in figure 2 can be seen depending on the lattice structure of the nanoparticles. From XRD and TEM measurements the lattice structure of the two larger thiolcapped samples is predominantly hexagonal whereas the two smaller ones show the cubic phase. In contrast, polyphosphate stabilized samples are cubic and slightly contracted with respect to cubic CaS bulk.

The static disorder in all samples is enlarged with respect to CdS bulk and shows a maximum for nanoparticles about $30 \AA$ in size. Smaller nanoparticles can partly be isolated as macrocrystalline samples with known structure from SC-XRD [6], [7] which show a very ordered surface whereas particles of intermediate size have obviously a more distorted surface.
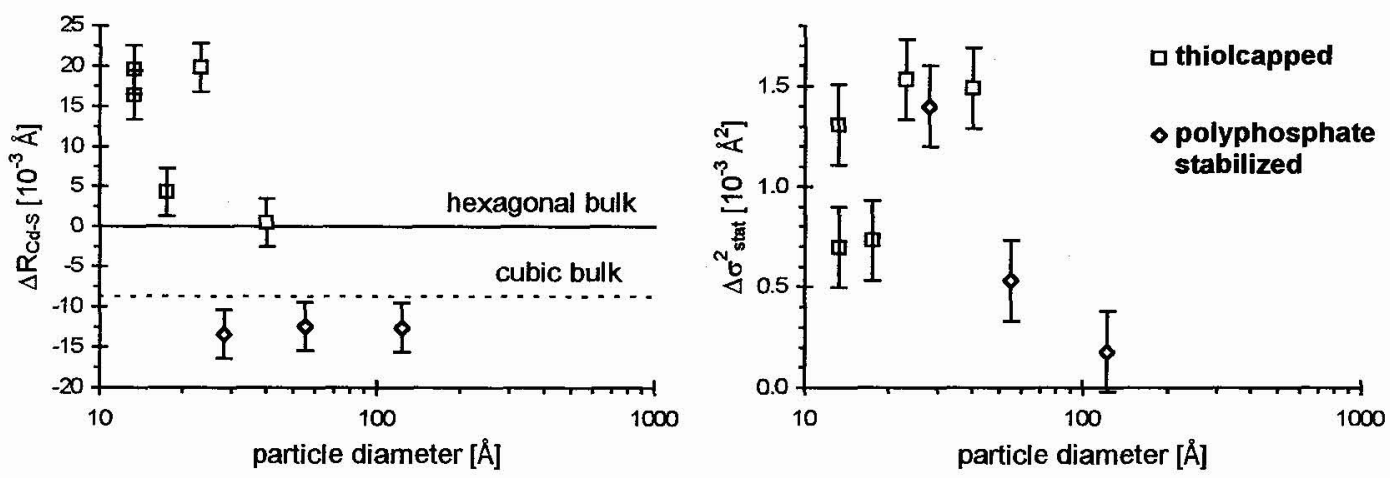

Figure 2: Cd-S distance shift, $\Delta \mathrm{R}_{\mathrm{Cd-S}}$, and the shift of the static disorder $\Delta \sigma^{2}$ stat, with respect to hexagonal CdS bulk.

The influence of the surface can also be seen in the fit results of the Debye temperature $T_{D}$ and the third moment $C_{3}$ of the Cd-S pair distribution function. With decreasing particle size $T_{D}$ and $C_{3}$ increase reflecting a stiffening of the Cd-S bond and a more asymmetric arrangement of the S-atoms surrounding the Cd-atoms. An interesting dependence of the absolute value of $\mathrm{C}_{3}$ from the lattice structure of the nanoparticles is observed. In nanoparticles with cubic zincblende structure of the $\mathrm{CdS}$ cluster core their $C_{3}$ is generally lowered with respect to the hexagonal $40 \AA$ nanoparticles and CdS bulk. This observation can be explained by the more symmetric arrangement of neighbor atoms in the cubic zincblende structure with four equivalent distances in comparison to the hexagonal wurtzite structure with three equal and one different distance. This indicates that the third cumulant allows to determine the lattice structure in small nanoparticles [8].

\section{References}

[1] Voßmeyer T., Katsikas L., Giersig M., Popovic I.G., Diesner K., Chemsedinne A., Eychmüller A., Weller H., J. Phys. Chem. 98 (1994) $7665-7673$

[2] Spanhel L., Haase M., Weller H., Henglein A., J. Am.Chem. Soc. 109 (1987) 5649 - 5655

[3] Voßmeyer T., Reck G., Katsikas L., Haupt E.T.K., Schulz B., Weller H., Inorg. Chem. 34 (1995) 4926 - 4929

[4] Rehr J.J., Albers, R. C., Zabinsky S.I., Phys. Rev. Lett. 69 (1992) 3397 - 3405

[5] Stem E.A., Newville M., Ravel B., Yacoby Y., Haskel D., Physica B 208-209 (1995) 117 - 123

[6] Voßmeyer T., Reck G., Katsikas L., Haupt E.T.K., Schulz B., Weller H., Science 267 (1995) 1476 - 1479

[7] VoBmeyer T., Reck G., Schulz B., Katsikas L., Weller H., J. Am. Chem. Soc. 117 (1995) 12881 - 12885

[8] A much more detailed presentation and discussion will be published soon. 